\title{
Low serum levels of bone turnover markers are associated with perirenal fat thickness in patients with type 2 diabetes mellitus
}

\author{
Xiaoxia Jia ${ }^{1,2}$, Yaxin An ${ }^{1,2}$, Yuechao Xu ${ }^{1,2}$, Yuxian Yang ${ }^{1,2}$, Chang Liu ${ }^{1,2}$, Dong Zhao ${ }^{1,2}$ and Jing $\mathrm{Ke}^{1,2}$ \\ ${ }^{1}$ Center for Metabolism and Immune Diseases, Beijing Luhe Hospital, Capital Medical University, Beijing, China \\ ${ }^{2}$ Beijing Key Laboratory of Diabetes Research and Care, Beijing, China \\ Correspondence should be addressed to J Ke: kejing@ccmu.edu.cn
}

\begin{abstract}
Background: Obesity is known as a common risk factor for osteoporosis and type 2 diabetes mellitus (T2DM). Perirenal fat, surrounding the kidneys, has been reported to be unique in anatomy and biological functions. This study aimed to explore the relationship between perirenal fat and bone metabolism in patients with T2DM. Methods: A total of 234 patients with T2DM were recruited from September 2019 to December 2019 in the cross-sectional study. The biochemical parameters and bone turnover markers (BTMs) were determined in all participants. Perirenal fat thickness (PrFT) was performed by ultrasounds via a duplex Doppler apparatus. Associations between PrFT and bone metabolism index were determined via correlation analysis and regression models.

Results: The PrFT was significantly correlated with $\beta$-C-terminal telopeptides of type I collagen ( $\beta$-CTX) $(r=-0.14, P<0.036)$, parathyroid hormone (iPTH) $(r=-0.18, P \leq 0.006)$, and 25 hydroxyvitamin $D(25-\mathrm{OH}-\mathrm{D})(\mathrm{r}=-0.14, P=0.001)$. Multivariate analysis confirmed that the association of PrFT and $\beta$-CTX ( $\beta=-0.136, P=0.042)$ was independent of other variables.

Conclusion: This study showed a negative and independent association between PrFT and $\beta$-CTX in subjects with T2DM, suggesting a possible role of PrFT in bone metabolism. Follow-up studies and further research are necessary to validate the associations and to elucidate the underlying mechanisms.
\end{abstract}

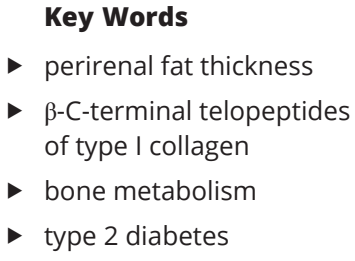

Endocrine Connections (2021) 10, 1337-1343

\section{Introduction}

Osteoporosis and related fractures commonly exist in patients with type 2 diabetes mellitus (T2DM), which results in a great economic and social burden in the aging society (1). It has been reported that diabetes mellitus was an independent risk factor of low-energy subtrochanteric and diaphyseal fractures (2). Growing evidence, including population-based observational and longitudinal cohort studies, has linked T2DM to osteoporosis and even higher fracture incidence $(3,4,5,6,7)$. In fact, T2DM and osteoporosis shared many common risk factors including obesity, BMI, glucocorticoid exposure and genetic factors (8).
Obesity has been considered as an abnormal or excessive fat accumulation. Studies of adipocyte function have revealed that adipose tissue is not just an inert organ for energy storage. It expresses and secretes a variety of biologically active molecules, such as estrogen, resistin, leptin, adiponectin, and interleukin-6 (IL-6). These molecules affect human energy homeostasis and may be involved in bone metabolism, which may contribute to the complex relationship between fat mass and bone (9). Although amounts of studies showed either a clear positive or negative effect of whole-body fat mass on bone, regional

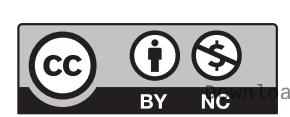

This work is licensed under a Creative Commons Attribution-NonCommercial 4.0 International License. ded from Bioscientifica.com at $04 / 26 / 2023$ 02:04:53PM 
fat distribution may also influence bone mass, independent of total body fat mass (10). Subcutaneous and visceral fat have different metabolic profiles, and pro-inflammatory cytokines from visceral fat such as IL- 6 and tumour necrosis factor alpha (TNF- $\alpha$ ) increase bone resorption, and so may have harmful effects on BMD (11).

Perirenal fat is a fat pad surrounding the kidneys, located between the renal fibrous membrane and the renal fascia in the retroperitoneal space (12). Anatomy studies have confirmed that perirenal fat has a complete system of blood supply, lymph fluid drainage, and innervation compared to classically connective tissues $(13,14,15)$. Histologically, paranephric fat is a typical white adipose tissue depot, while perirenal fat mainly consists of dormant brown adipose tissue (16). However, perirenal fat is more active in energy metabolism and adipokine secretion compared with typical visceral fat (12). It has been proved that massive perirenal fat thickness (PrFT) was an early predictor of atherosclerosis (17). De Pergola and colleagues have found a positive association between para- and perirenal fat thickness and mean $24 \mathrm{~h}$ diastolic blood pressure level in overweight and obese subjects (18).

Many studies have described the effect of obesity and T2DM on fracture risk and explored possible mechanisms of their effects, whereas the relation between PrFT and bone metabolism is not currently available. So, our study aimed to explore the relationship between perirenal fat and bone metabolism in patients with T2DM, expecting to provide a unique explanation for the innumerable links between obesity and bone metabolism.

\section{Methods}

\section{Subject population}

The study subjects were consecutively enrolled at the Metabolism and Immune Disease Center of Beijing Luhe Hospital, Capital Medical University from September 2019 to December 2019. A total of 234 patients with T2DM including 116 females and 118 males were included. The diagnosis of T2DM was defined according to 1999 World Health Organization Criteria (19), which include fasting blood glucose $\geq 7.0 \mathrm{mmol} / \mathrm{L}$ and/or 2-h blood glucose during a $75 \mathrm{~g}$ oral glucose tolerance test (OGTT) $\geq 11.1 \mathrm{mmol} / \mathrm{L}$. Patients with endocrinological diseases, chronic inflammatory diseases, stable hypertension, angina pectoris, stroke, transient ischemic attack, heart infarction and congenital heart disease were excluded.
All procedures performed in studies involving human participants were in accordance with the ethical standards of the institutional and/or national research committee and with the 1964 Helsinki declaration and its later amendments or comparable ethical standards. The study was approved by Ethics Committee of Beijing Luhe Hospital.

\section{General data and anthropometric measurements}

We recorded baseline data including age, gender, duration of diabetes, as well as detailed information of medical history for each patient. BMI was calculated as the weight divided by the square of height. Waist circumference was measured at the anatomic waistline, that should be the narrowest part of the abdomen, which is at the natural indentation between the iliac crest and the tenth rib (minimum waist). Abdominal visceral fat area (VFA) was simultaneously quantified by DUALSCAN HDS-2000 (OMRON Healthcare Co, Kyoto, Japan), which is an abdominal dual machine using bioelectrical impedance analysis.

An auto-biochemical analyzer (Roche/Hitachi Cobas C501, Roche Diagnostic Corp.) was employed to determine serum concentrations of total cholesterol (TC), triglyceride (TG), low-density lipoprotein cholesterol (LDL-C), highdensity lipoprotein cholesterol (HDL-C) and uric acid. Glycosylated hemoglobin (HbA1c) concentrations were quantified using highperformance liquid chromatography (HPLC) with a D10 set (Bio-RAD). Estimated glomerular filtration rate (eGFR) is calculated using the MDRD formula $\left(\mathrm{GFR}\left(\mathrm{mL} / \mathrm{min} / 1.73 \mathrm{~m}^{2}\right)=175 \times(\mathrm{Scr} / 88.4)^{-1.154} \times(\text { Age })^{-0.203} \times\right.$ (0.742 if female)).

Fasting serum insulin, serum BTMs, including uncarboxylated osteocalcin (OC), procollagen type I $\mathrm{N}$-terminal propeptide (TP1NP), and $\beta$-cross-linked C-telopeptide of type I collagen ( $\beta$-CTX); intact parathyroid hormone (iPTH); and 25 hydroxyvitamin D (25-OH-D) were evaluated by the electrochemiluminescence immunoassay method on a Roche COBAS E 801 (Roche Diagnostics Corporation).

\section{Measurement of PrFT}

Measurement of PrFT was performed as previously described by our group (20), and ultrasound examinations were performed by a duplex Doppler apparatus (HITACHI HI VISION Preirus). PrFT and paranephric fat thickness (PnFT) were measured with the patient in the supine position. The probe was kept perpendicular to the skin on 
the lateral aspect of the abdomen. Longitudinal scanning was performed, and the probe was slowly moved laterally until the optimal position was found, at which the surface of the kidney was almost parallel to the skin. The pressure exerted on the probe was as minimal as possible so that the fat layers were not compressed. PrFT and PnFT were then determined from the inner side of the abdominal musculature to the surface of the kidney. The average of bilateral ultrasound measurements was calculated as the PrFT and PnFT. The correlation between PrFT values measured on both sides was $0.676(P<0.0001)$. The sonographer (Yuechao $\mathrm{Xu}$ ) was blinded to any other aspect of the study.

\section{Statistical analysis}

Measurement data are represented by mean \pm S.D. or median (interquartile range), count data are represented by $\chi^{2}$ test, comparison between groups is by $t$ test or ANOVA, the correlation analysis uses Spearman correlation analysis method. In addition, in order to test the independent relationship between $\beta$-CTX and other test parameters, a multivariate model was constructed using multiple linear regression analysis based on $\beta$-CTX (dependent variable) and univariate significance variables. Significant independent variables are determined through an enter method, and a final model with sufficient statistical power is constructed. The data are expressed as unstandardized regression coefficients (B) and standardized regression coefficients ( $\beta$ ). SPSS22.0 software was used for statistical processing. $P<0.05$ was considered statistically significant.

\section{Results}

\section{Clinical characteristics of the subjects}

Characteristics of the overall the study population are shown in Table 1 . The study population included 116 females and 118 males, whose age median was $61(49,70)$ years, and their diabetes duration was $10(3,15)$ years. Meanwhile, our subjects had a higher BMI so the mean value was $26.7 \pm 4.3 \mathrm{~kg} / \mathrm{m}^{2}$. Besides, some laboratory test indicators, like visceral fat, blood lipids, glycosylated hemoglobin and blood uric acid were shown. The median of $\beta$-CTX was $0.35(0.24,0.53) \mathrm{ng} / \mathrm{mL}$, the median of osteocalcin was $10.3(8.1,13.2) \mathrm{ng} / \mathrm{mL}$, the median of TP1NP was $38.3(28.8,49.2) \mathrm{ng} / \mathrm{mL}$, the median of iPTH was $29.9(23.9,37.8) \mathrm{pg} / \mathrm{mL}$, and the mean value of PrFT in 234 patients with T2DM was $0.98 \pm 0.49 \mathrm{~cm}$.
Table 1 Characteristics of the overall study population.

\begin{tabular}{l} 
Parameters \\
\hline Sex (males/females) \\
Age (year) \\
Diabetes duration (year) \\
BMI $\left(\mathrm{kg} / \mathrm{m}^{2}\right)$ \\
WC $(\mathrm{cm})$ \\
VFA $\left(\mathrm{cm}^{2}\right)$ \\
TG $(\mathrm{mmol} / \mathrm{L})$ \\
TC $(\mathrm{mmol} / \mathrm{L})$ \\
HDL-c $(\mathrm{mmol} / \mathrm{L})$ \\
LDL-c $(\mathrm{mmol} / \mathrm{L})$ \\
eGFR $\left(\mathrm{mL} / \mathrm{min} / 1.73 \mathrm{~m}^{2}\right)$ \\
UA $(\mu \mathrm{mol} / \mathrm{L})$ \\
HbA1c $(\%)$ \\
OC $(\mathrm{ng} / \mathrm{mL})$ \\
TP1 NP $(\mathrm{ng} / \mathrm{mL})$ \\
$\beta-C T X(\mathrm{ng} / \mathrm{mL})$ \\
iPTH $(\mathrm{pg} / \mathrm{mL})$ \\
$25-O H-D(n g / m L)$ \\
$\operatorname{PrFT~}(\mathrm{cm})$ \\
PnFT $(\mathrm{cm})$ \\
\hline
\end{tabular}

\begin{tabular}{c}
\hline \\
\hline $118 / 116$ \\
$61(49,70)$ \\
$10(3,15)$ \\
$26.7 \pm 4.3$ \\
$96.1 \pm 11.2$ \\
$103(79,140)$ \\
$1.44(1.05,2.03)$ \\
$4.10(3.36,5.08)$ \\
$1.02(0.87,1.22)$ \\
$2.86 \pm 1.08$ \\
$96.5(80.0,112)$ \\
$332 \pm 101$ \\
$9.3 \pm 2.2$ \\
$10.3(8.1,13.2)$ \\
$38.3(28.8,49.2)$ \\
$0.35(0.24,0.53)$ \\
$29.9(23.9,37.8)$ \\
$12.9(9.6,18.0)$ \\
$0.98 \pm 0.49$ \\
$1.01 \pm 0.41$
\end{tabular}

Data are represented by mean \pm S.D. or median (interquartile range). 25-OH-D, 25 hydroxyvitamin D; eGFR, estimated glomerular filtration rate; HbA1c, glycated hemoglobin; HDL-c, high-density lipoprotein-cholesterol; iPTH, intact parathyroid hormone; LDL-c, low-density lipoproteincholesterol; OC, osteocalcin; PnFT, paranephric fat thickness; PrFT, perirenal fat thickness; TC, total cholesterol; TG, triglyceride; TP1NP, procollagen type I N-terminal propeptide; UA, uric acid; VFA, visceral fat area; WC, waist circumference; $\beta$-CTX, $\beta$-cross-linked C-telopeptide of type I collagen.

\section{Correlations between PrFT and all the parameters}

Table 2 showed the correlation between PrFT and all other parameters in 234 patients. The PrFT was significantly and positively correlated with $\operatorname{sex}(\mathrm{r}=0.33, P<0.001), \mathrm{BMI}(\mathrm{r}=0.40$, $P<0.001)$, waist circumference $(\mathrm{r}=0.46, P<0.001)$, visceral fat area $(\mathrm{r}=0.55, P<0.001)$, triglyceride $(\mathrm{r}=0.23, P<0.001)$, high-density lipoprotein-cholesterol $(\mathrm{r}=-0.26, P<0.001)$, uric acid $(\mathrm{r}=-0.26, P<0.001), \beta-\mathrm{CTX}(\mathrm{r}=-0.14, P<0.036)$, iPTH $(\mathrm{r}=-0.18, P \leq 0.006)$, and $25-\mathrm{OH}-\mathrm{D}(\mathrm{r}=-0.14, P=0.001)$, whereas no correlation was found between PrFT and osteocalcin $(\mathrm{r}=-0.07, P=0.287), \mathrm{TP} 1 \mathrm{NP}(\mathrm{r}=-0.04, P=0.593)$ or some general data and anthropometric measurements, such as age, diabetes duration, TC, LDL-c and HbA1c.

\section{Correlations between $\beta$-CTX and all other parameters}

Then we analyzed the correlation between $\beta$-CTX and all other parameters in all subjects. The $\beta$-CTX was significantly and positively correlated with OC $(\mathrm{r}=0.66, P<0.001)$, TP1NP $(\mathrm{r}=0.66, P<0.001)$, PTH $(\mathrm{r}=0.28, P<0.001)$, diabetes duration $(\mathrm{r}=-0.18, P=0.007)$ and $\operatorname{PrFT}(\mathrm{r}=-0.14$,

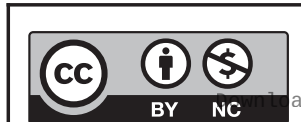

This work is licensed under a Creative Commons Attribution-NonCommercial 4.0 International License. ded from Bioscientifica.com at 04/26/2023 02:04:53PM 
Table 2 Correlations between PrFT and other parameters in subjects.

\begin{tabular}{l} 
Parameter \\
Sex (males/females) \\
Age (year) \\
Diabetes duration (year) \\
BMI $\left(\mathrm{kg} / \mathrm{m}^{2}\right)$ \\
WC $(\mathrm{cm})$ \\
VFA $\left(\mathrm{cm}^{2}\right)$ \\
TG $(\mathrm{mmol} / \mathrm{L})$ \\
TC $(\mathrm{mmol} / \mathrm{L})$ \\
HDL-c $(\mathrm{mmol} / \mathrm{L})$ \\
LDL-c $(\mathrm{mmol} / \mathrm{L})$ \\
UA $(\mu \mathrm{mol} / \mathrm{L})$ \\
eGFR $\left(\mathrm{ml} / \mathrm{min} / 1.73 \mathrm{~m}^{2}\right)$ \\
HbA1c $(\%)$ \\
OC $(\mathrm{ng} / \mathrm{mL})$ \\
TP1NP $(\mathrm{ng} / \mathrm{mL})$ \\
$\beta-C T X(\mathrm{ng} / \mathrm{mL})$ \\
iPTH $(\mathrm{pg} / \mathrm{mL})$ \\
$25-O H-D(\mathrm{ng} / \mathrm{mL})$ \\
\hline
\end{tabular}

\begin{tabular}{ccrr}
\hline \multicolumn{1}{c}{$\boldsymbol{r}$} & & P value \\
\cline { 1 - 1 }$-0.33^{\mathrm{b}}$ & & $<0.001$ \\
0.06 & & 0.340 \\
0.06 & & 0.401 \\
$0.40^{\mathrm{b}}$ & & $<0.001$ \\
$0.46^{\mathrm{b}}$ & & $<0.001$ \\
$0.55^{\mathrm{b}}$ & & $<0.001$ \\
$0.23^{\mathrm{b}}$ & & $<0.001$ \\
-0.11 & & 0.096 \\
$-0.26^{\mathrm{b}}$ & & $<0.001$ \\
-0.08 & & 0.206 \\
$-0.26^{\mathrm{b}}$ & & $<0.001$ \\
$-0.16^{\mathrm{a}}$ & & 0.018 \\
-0.13 & & 0.054 \\
-0.07 & & 0.287 \\
-0.04 & & 0.593 \\
$-0.14^{\mathrm{a}}$ & & 0.036 \\
$-0.18^{\mathrm{a}}$ & & 0.006 \\
$-0.14^{\mathrm{a}}$ & & 0.036 \\
\hline
\end{tabular}

${ }^{a} P<0.05,{ }^{b} P<0.01, r$ represents the Spearman correlation coefficient. 25-OH-D, 25 hydroxyvitamin D; eGFR, estimated glomerular filtration rate; HbA1c, glycated hemoglobin; HDL-c, high-density lipoproteincholesterol; iPTH, intact parathyroid hormone; LDL-c, low-density lipoprotein-cholesterol; OC, osteocalcin; $\mathrm{PnFT}$, paranephric fat thickness; PrFT, perirenal fat thickness; TC, total cholesterol; TG, triglyceride; TP1NP, procollagen type I N-terminal propeptide; UA, uric acid; VFA, visceral fat area; WC, waist circumference; $\beta$-CTX, $\beta$-cross-linked C-telopeptide of type I collagen.

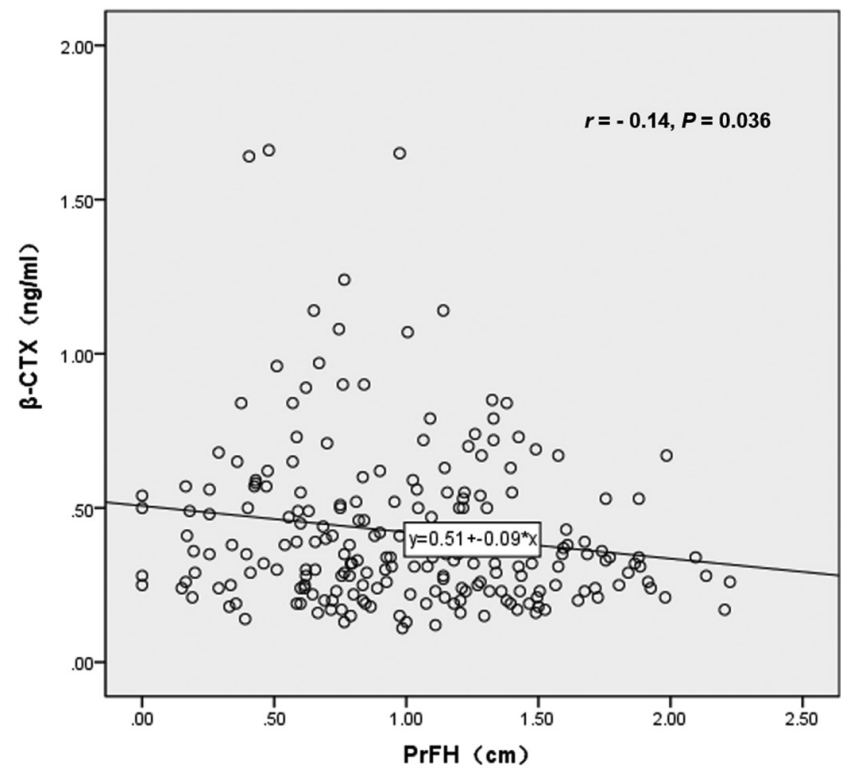

Figure 1

Correlations between PrFT and $\beta$-CTX overall study population. Note: $\beta$-CTX, $\beta$-cross-linked C-telopeptide of type I collagen; PrFT, perirenal fat thickness.
$P<0.036$ ) (Fig. 1), and negatively with PnFT, sex, age, BMI, visceral fat area and 25-OH-D (Table 3).

\section{Multivariate analysis after correction for the confounding factors}

As shown in Table 4, a multivariate model was constructed using multiple linear regression analysis based on $\beta$-CTX (dependent variable) and univariate significance variables. We confirmed that PrFT was independent and negatively associated with $\beta$-CTX ( $\beta=-0.136, P=0.042)$ after adjusting other confounding factors, such as age, sex, diabetes duration, TP1NP, triglyceride and eGFR.

\section{Discussion}

The most important finding of our study is that PrFT is negatively correlated with $\beta$-CTX in T2DM patients, and this correlation remained significant after adjusting other confounding factors.

There is no existing evidence for the role of PrFT in bone metabolism. While ample evidence supports the view that fat mass, a component of total body weight and one of the most important indices of obesity, has a similar

Table 3 Correlations between $\beta$-CTX and other parameters.

\begin{tabular}{l} 
Parameter \\
\hline Sex (males/females) \\
Age (year) \\
Diabetes duration (year) \\
BMI $\left(\mathrm{kg} / \mathrm{m}^{2}\right)$ \\
WC $(\mathrm{cm})$ \\
VFA $\left(\mathrm{cm}^{2}\right)$ \\
TG $(\mathrm{mmol} / \mathrm{L})$ \\
TC $(\mathrm{mmol} / \mathrm{L})$ \\
HDL-c $(\mathrm{mmol} / \mathrm{L})$ \\
LDL-c $(\mathrm{mmol} / \mathrm{L})$ \\
eGFR $\left(\mathrm{mL} / \mathrm{min} / 1.73 \mathrm{~m}^{2}\right)$ \\
UA $(\mu \mathrm{mol} / \mathrm{L})$ \\
HbA1c $(\%)$ \\
OC $(\mathrm{ng} / \mathrm{mL})$ \\
TP1NP $(\mathrm{ng} / \mathrm{mL})$ \\
iPTH $(\mathrm{pg} / \mathrm{mL})$ \\
$25-O H-D(\mathrm{ng} / \mathrm{mL})$ \\
PrFT $(\mathrm{cm})$ \\
PnFT $(\mathrm{cm})$
\end{tabular}

\begin{tabular}{cccc}
\hline \multicolumn{1}{c}{$\boldsymbol{r}$} & & P value \\
\cline { 1 - 1 } 0.11 & & 0.119 \\
-0.07 & & 0.340 \\
$-0.18^{\mathrm{b}}$ & & 0.007 \\
-0.07 & & 0.308 \\
-0.03 & & 0.686 \\
-0.07 & & 0.370 \\
0.09 & & 0.180 \\
0.07 & & 0.315 \\
-0.05 & & 0.450 \\
0.09 & & 0.211 \\
$-0.14^{\mathrm{a}}$ & & 0.036 \\
-0.01 & & 0.872 \\
0.03 & & 0.714 \\
$0.66^{\mathrm{b}}$ & & $<0.001$ \\
$0.66^{\mathrm{b}}$ & & $<0.001$ \\
$0.28^{\mathrm{b}}$ & & $<0.001$ \\
-0.03 & & 0.715 \\
$-0.14^{\mathrm{a}}$ & & 0.036 \\
-0.08 & & 0.224 \\
\hline
\end{tabular}

ap $<0.05$, b $P<0.01, r$ represents the Spearson correlation coefficient. 25-OH-D, 25 hydroxyvitamin D; eGFR, estimated glomerular filtration rate; HbA1c, glycated hemoglobin; HDL-c, high-density lipoprotein-cholesterol; IPTH, intact parathyroid hormone; LDL-c, low-density lipoprotein-cholesterol; OC, osteocalcin; PnFT, paranephric fat thickness; PrFT, perirenal fat thickness; $\mathrm{TC}$, total cholesterol; TG, triglyceride; TP1NP, procollagen type I N-terminal propeptide; UA, uric acid; VFA, visceral fat area; WC, waist circumference; $\beta$-CTX, $\beta$-cross-linked C-telopeptide of type I collagen.

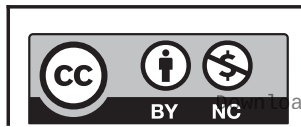

This work is licensed under a Creative Commons Attribution-NonCommercial 4.0 International License. ded from Bioscientifica.com at 04/26/2023 02:04:53PM 
Table 4 Multiple linear regression between $\beta$-CTX and PrFT in subjects under study.

\begin{tabular}{|c|c|c|c|c|}
\hline & $\begin{array}{l}\text { Unstandardized } \\
\text { coefficient }(\mathrm{B})\end{array}$ & $\begin{array}{l}\text { Standardized } \\
\text { coefficient }(\beta)\end{array}$ & $\mathbf{T}$ & $P$ value \\
\hline $\operatorname{PrFT}(\mathrm{cm})$ & -0.087 & $-0.136^{a}$ & -1.345 & 0.042 \\
\hline
\end{tabular}

The model was adjusted other confounding factors, such as age, sex, diabetes duration, TP1NP, TG and eGFR.

ap $<0.05$.

PrFT, perirenal fat thickness.

beneficial effect on increasing bone mass, thereby reducing the risk of osteoporosis, a longitudinal study showed that changes in BMD at most sites were positively related to the rate of change in fat mass $(21,22)$, and the EPIC study also showed that 'rapid' bone losers had significantly lower fat mass than the 'slow' bone losers (23). Some insight into how obesity may exert effects on bone can be obtained from biochemical markers of bone turnover. Compared to obesity, the difference in resorption markers may be greater than the difference in formation markers in those of normal weight (24). As we know, regional fat distribution may also influence bone mass (10). Subcutaneous and visceral fat have different metabolic profiles, and proinflammatory cytokines from visceral fat such as IL- 6 and TNF- $\alpha$ increase bone resorption and so may have harmful effects on BMD (11). But our study has shown that $\beta$-CTX, a resorption marker, is negatively associated with VFA $(\mathrm{r}=-0.07, P=0.370)$, the relationship may vary with age and gender $(25,26,27)$.

Considering the differences in the structure and function of perirenal fat and paranephric fat, our study analyzed PrFT and PnFT separately and finally found that it was PrFT related to $\beta$-CTX rather than PnFT. This is mainly due to the fact that perirenal fat directly surrounds the kidney and has a complete system of blood supply, lymph fluid drainage, and innervation compared with other fat depots, which contributes to the uniqueness of perirenal fat while $\beta$-CTX is widely accepted to be a characteristic biomarker of bone resorption and osteoclast activity as well as a predictor of bone fracture in patients with diabetes (28). A clinical study documented the positive association between $\beta$-CTX and HbA1c in women with normal glucose tolerance, suggesting that bone may serve as a protective compensatory mechanism against subtle increases in HbA1c until the development of diabetes (29). Similarly, we observed a positive relationship between $\beta$-CTX and HbA1c ( $r=0.03, P=0.714)$, although statistically insignificant.

As we all know, perirenal fat is highly active in adipokine synthesis, especially those regulating bone metabolism. Adiponectin, an adipokine, has been shown to have a deleterious effect on bone metabolism $(30,31)$. Kamil et al. (30) showed that adiponectin at higher levels may have a direct influence on bone turnover and remodeling. The risk of fracture with greater levels of adiponectin may reflect greater osteoclast activation and bone resorption. Adiponectin is known to be inversely related to BMI, and it is currently considered as a marker of a disrupted adaptive response in overweight patients $(30,31)$. In the Health Aging and Body Composition Study, serum level of adiponectin was higher in overweight women with fracture than those without fracture (32). Another important factor is leptin, another adipokine, which has been demonstrated to interfere with bone metabolism through various mechanisms $(32,33)$. The leptin-mediated melanocortin-signaling pathways may contribute to bone resorption but not bone formation $(32,33)$. Besides, leptin inhibits bone formation through a central nervous effect (34). Moreover, adipose tissue also produces inflammatory cytokines, such as interleukin-6 (IL6), that may negatively interfere with the balance between bone resorption and formation $(30,31)$.

Besides, many investigators have explored the association between PrFT and metabolism. PrFT has been confirmed to be related to metabolic risk factors such as UA, HDL-c, and TG (20), which is consistent with our results. The wide use of hypoglycemia agents in our study may explain the inconsistency. One study by Lamacchia and colleagues suggested that there was no significant relationship between PrFT and LDL-c in patients with T2DM (35), a similar result was found between PrFT and LDL-c in our research as well.

Above all, our study shows that PrFT is negatively correlated with $\beta$-CTX, a product of bone destruction, which means PrFT may positively interfere with the balance between bone resorption and formation. The mechanism may be related to the above-mentioned various factors secreted by PrFT, but the regulation of PrFT on bone metabolism still requires further clinical trials to explore further.

There are some limitations in our study as well. First, as our study is cross-sectionally designed, it could not establish a causal relationship between PrFT and $\beta$-CTX. Further studies are needed to illuminate the specific mechanism. Last, we measured PrFT and PnFT by ultrasonography instead of CT. Since ultrasonography is more convenient, fast to measure, and without radiation, it is widely utilized in clinical practice. According to a previous study (36), the intraoperator coefficient of variation was $4.5 \%$. However, follow-up studies and further research are necessary to validate the associations and elucidate the underlying mechanisms.

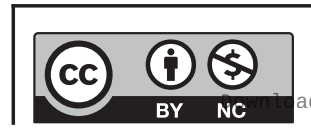

This work is licensed under a Creative Commons Attribution-NonCommercial 4.0 International License. ded from Bioscientifica.com at 04/26/2023 02:04:53PM 


\section{Conclusion}

In conclusion, this study showed a negative association between PrFT and $\beta$-CTX, after adjusting other confounding factors, such as age, sex, diabetes duration, TP1NP, TG and eGFR. Follow-up studies and further research are necessary to validate the associations and to elucidate the underlying mechanisms.

\section{Declaration of interest}

The authors declare that there is no conflict of interest that could be perceived as prejudicing the impartiality of the research reported.

\section{Funding}

This work did not receive any specific grant from funding agencies in the public, commercial, or not-for-profit sectors.

\section{Ethics approval and consent to participate}

All procedures performed in studies involving human participants were in accordance with the ethical standards of the institutional and/or national research committee and with the 1964 Helsinki declaration and its later amendments or comparable ethical standards. The study was approved by Ethics Committee of Beijing Luhe Hospital. This article does not contain any studies with animals performed by any of the authors.

\section{Data availability}

The data used to support the findings of this study are available from the corresponding author upon request.

\section{References}

1 Sellmeyer DE, Civitelli R, Hofbauer LC, Khosla S, Lecka-Czernik B \& Schwartz AV. Skeletal metabolism, fracture risk, and fracture outcomes in type 1 and type 2 diabetes. Diabetes 201665 1757-1766. (https://doi. org/10.2337/db16-0063)

2 Napoli N, Schwartz AV, Palermo L, Jin JJ, Wustrack R, Cauley JA, Ensrud KE, Kelly M \& Black DM. Risk factors for subtrochanteric and diaphyseal fractures: the study of osteoporotic fractures. Journal of Clinical Endocrinology and Metabolism 201398 659-667. (https://doi. org/10.1210/jc.2012-1896)

3 Jia P, Bao L, Chen H, Yuan J, Liu W, Feng F, Li J \& Tang H. Risk of low-energy fracture in type 2 diabetes patients: a meta-analysis of observational studies. Osteoporosis International 201728 3113-3121. (https://doi.org/10.1007/s00198-017-4183-0)

$4 \mathrm{Ni} \mathrm{Y} \mathrm{\&} \mathrm{Fan} \mathrm{D.} \mathrm{Diabetes} \mathrm{mellitus} \mathrm{is} \mathrm{a} \mathrm{risk} \mathrm{factor} \mathrm{for} \mathrm{low} \mathrm{bone} \mathrm{mass-}$ related fractures: a meta-analysis of cohort studies. Medicine 201796 e8811. (https://doi.org/10.1097/MD.0000000000008811)

5 Koh WP, Wang R, Ang LW, Heng D, Yuan JM \& Yu MC. Diabetes and risk of hip fracture in the Singapore Chinese Health Study. Diabetes Care 201033 1766-1770. (https://doi.org/10.2337/dc10-0067)

6 Tebé C, Martinez-Laguna D, Moreno V, Cooper C, Diez-Perez A, Collins GS \& Prieto-Alhambra D. Differential mortality and the excess rates of hip fracture associated with type 2 diabetes: accounting for competing risks in fracture prediction matters. Journal of Bone and Mineral Research 201833 1417-1421. (https://doi.org/10.1002/ jbmr.3435)
7 Jiajue RZ, Qi X, Jiang Y, Wang QP, Wang WB, Pei Y, Wang XR, Huang W, Zheng $X$, Ning ZW, et al. Incident fracture risk in type 2 diabetic postmenopausal women in mainland China: Peking Vertebral Fracture Study. Calcified Tissue International 2019105 466-475. (https://doi. org/10.1007/s00223-019-00598-x)

8 Jackuliak P \& Payer J. Osteoporosis, fractures, and diabetes. International Journal of Endocrinology 20142014 820615. (https://doi. org/10.1155/2014/820615)

9 Rosen CJ \& Bouxsein ML. Mechanisms of disease: is osteoporosis the obesity of bone? Nature Clinical Practice: Rheumatology 20062 35-43. (https://doi.org/10.1038/ncprheum0070)

10 Tarquini B, Navari N, Perfetto F, Piluso A, Romano S \& Tarquini R. Evidence for bone mass and body fat distribution relationship in postmenopausal obese women. Archives of Gerontology and Geriatrics 199724 15-21. (https://doi.org/10.1016/s0167-4943(96)00723-6)

11 Morley JE \& Baumgartner RN. Cytokine-related aging process. Journals of Gerontology: Series A, Biological Sciences and Medical Sciences 200459 M924-M929. (https://doi.org/10.1093/gerona/59.9.m924)

12 Liu BX, Sun W \& Kong XQ. Perirenal fat: a unique fat pad and potential target for cardiovascular disease. Angiology 2019 70 584-593. (https://doi.org/10.1177/0003319718799967)

13 Kim JH, Han EH, Jin ZW, Lee HK, Fujimiya M, Murakami G \& Cho BH. Fetal topographical anatomy of the upper abdominal lymphatics: its specific features in comparison with other abdominopelvic regions. Anatomical Record 2012295 91-104. (https://doi.org/10.1002/ ar.21527)

14 Hausman GJ. Anatomical and enzyme histochemical differentiation of adipose tissue. International Journal of Obesity 19859 (Supplement 1) 1-6.

15 Czaja K, Kraeling R, Klimczuk M, Franke-Radowiecka A, Sienkiewicz W \& Lakomy M. Distribution of ganglionic sympathetic neurons supplying the subcutaneous, perirenal and mesentery fat tissue depots in the pig. Acta Neurobiologiae Experimentalis 200262 227-234.

16 Jespersen NZ, Feizi A, Andersen ES, Heywood S, Hattel HB, Daugaard S, Peijs L, Bagi P, Feldt-Rasmussen B, Schultz HS, et al. Heterogeneity in the perirenal region of humans suggests presence of dormant brown adipose tissue that contains brown fat precursor cells. Molecular Metabolism 201924 30-43. (https://doi.org/10.1016/j. molmet.2019.03.005)

17 Grima P, Guido M, Zizza A \& Chiavaroli R. Sonographically measured perirenal fat thickness: an early predictor of atherosclerosis in HIV-1infected patients receiving highly active antiretroviral therapy? Journal of Clinical Ultrasound 201038 190-195. (https://doi.org/10.1002/ jcu.20664)

18 Pergola GD, Campobasso N, Nardecchia A, Triggiani V, Caccavo D, Gesualdo L, Silvestris F \& Manno C. Para- and perirenal ultrasonographic fat thickness is associated with 24-hours mean diastolic blood pressure levels in overweight and obese subjects. $B M C$ Cardiovascular Disorders 201515 108. (https://doi.org/10.1186/s12872015-0101-6)

19 World Health Organization. Definition, Diagnosis and Classification of Diabetes Mellitus and Its Complications. Report of a WHO Consultation. Part 1: Diagnosis and Classification of Diabetes Mellitus, pp. 1-59. Geneva, Switzerland: WHO Department of Noncommunicable Disease Surveillance, 1999.

20 Fang Y, Xu YC, Yang YX, Liu C, Zhao D \& Ke J. The relationship between perirenal fat thickness and reduced glomerular filtration rate in patients with Type 2 diabetes. Journal of Diabetes Research 20202020 6076145. (https://doi.org/10.1155/2020/6076145)

21 Chen Z, Lohman TG, Stini WA, Ritenbaugh C \& Aickin M. Fat or lean tissue mass: which one is the major determinant of bone mineral mass in healthy postmenopausal women? Journal of Bone and Mineral Research 199712 144-151. (https://doi.org/10.1359/jbmr.1997.12.1.144)

22 Reid IR, Ames RW, Evans MC, Sharpe SJ \& Gamble GD. Determinants of the rate of bone loss in normal postmenopausal women. Journal of Clinical Endocrinology and Metabolism 199479 950-954. (https://doi. org/10.1210/jcem.79.4.7962303)

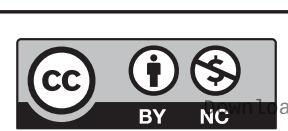

This work is licensed under a Creative Commons Attribution-NonCommercial 4.0 International License. ded from Bioscientifica.com at 04/26/2023 02:04:53PM 
23 Riis BJ, Rodbro P \& Christiansen C. The role of serum concentrations of sex steroids and bone turnover in the development and occurrence of ostmenopausal osteoporosis. Calcified Tissue International 198638 318-322. (https://doi.org/10.1007/BF02555743)

24 Garnero P, Sornay-Rendu E, Claustrat B \& Delmas PD. Biochemical markers of bone turnover, endogenous hormones and the risk of fractures in postmenopausal women: the OFELY study. Journal of Bone and Mineral Research 200015 1526-1536. (https://doi.org/10.1359/ jbmr.2000.15.8.1526)

25 Cohen A, Dempster DW, Recker RR, Lappe JM, Zhou H, Zwahlen A, Müller R, Zhao B, Guo X, Lang T, et al. Abdominal fat is associated with lower bone formation and inferior bone quality in healthy premenopausal women: a transiliac bone biopsy study. Journal of Clinical Endocrinology and Metabolism 201398 2562-2572. (https://doi. org/10.1210/jc.2013-1047)

26 Ng AC, Melton LJ, Atkinson EJ, Achenbach SJ, Holets MF, Peterson JM, Khosla S \& Drake MT. Relationship of adiposity to bone volumetric density and microstructure in men and women across the adult lifespan. Bone 201355 119-125. (https://doi.org/10.1016/j. bone.2013.02.006)

27 Zhang P, Peterson M, Su GL \& Wang SC. Visceral adiposity is negatively associated with bone density and muscle attenuation. American Journal of Clinical Nutrition $2015101337-343$. (https://doi.org/10.3945/ ajcn.113.081778)

28 Starup-Linde J \& Vestergaard P. Biochemical bone turnover markers in diabetes mellitus - a systematic review. Bone 201682 69-78. (https:// doi.org/10.1016/j.bone.2015.02.019)

29 Xuan Y, Sun LH, Liu DM, Zhao L, Tao B, Wang WQ, Zhao HY, Liu JM \& Ning G. Positive association between serum levels of bone resorption marker CTX and HbA1c in women with normal glucose tolerance. Journal of Clinical Endocrinology and Metabolism 2015100 274-281. (https://doi.org/10.1210/jc.2014-2583)
30 Zhao Y, Gao P, Sun F, Li Q, Chen J, Yu H, Li L, Wei X, He HB, Lu ZS, et al. Sodium intake regulates glucose homeostasis through the PPAR $\delta /$ adiponectin- mediated SGLT2 pathway. Cell Metabolism 201623 699-711. (https://doi.org/10.1016/j.cmet.2016.02.019)

31 Zhao LJ, Jiang H, Papasian CJ, Maulik D, Drees B, Hamilton J \& Deng HW. Correlation of obesity and osteoporosis: effect of fat mass on the determination of osteoporosis. Journal of Bone and Mineral Research 200823 17-29. (https://doi.org/10.1359/jbmr.070813)

32 Sukumar D, Schlussel Y, Riedt CS, Gordon C, Stahl T \& Shapses SA. Obesity alters cortical and trabecular bone density and geometry in women. Osteoporosis International 201122 635-645. (https://doi. org/10.1007/s00198-010-1305-3)

33 Barbour KE, Zmuda JM, Boudreau R, Strotmeyer ES, Horwitz MJ, Evans RW, Kanaya AM, Harris TB, Bauer DC \& Cauley JA. Adipokines and the risk of fracture in older adults. Journal of Bone and Mineral Research 201126 1568-1576. (https://doi.org/10.1002/jbmr.361)

34 Takeda S, Elefteriou F, Levasseur R, Liu X, Zhao L, Parker KL, Armstrong D, Ducy P \& Karsenty G. Leptin regulates bone formation via the sympathetic nervous system. Cell $2002111305-317$. (https:// doi.org/10.1016/s0092-8674(02)01049-8)

35 Lamacchia O, Nicastro V, Camarchio D, Valente U, Grisorio R, Gesualdo L \& Cignarelli M. Para- and perirenal fat thickness is an independent predictor of chronic kidney disease, increased renal resistance index and hyperuricaemia in type- 2 diabetic patients. Nephrology, Dialysis, Transplantation 201126 892-898. (https://doi. org/10.1093/ndt/gfq522)

36 Geraci G, Zammuto MM, Mattina A, Zanoli L, Geraci C, Granata A, Nardi E, Fatuzzo PM, Cottone $S$ \& Mulè G. Para-perirenal distribution of body fat is associated with reduced glomerular filtration rate regardless of other indices of adiposity in hypertensive patients. Journal of Clinical Hypertension 201820 1438-1446. (https://doi. org/10.1111/jch.13366)

Received in final form 7 September 2021

Accepted 17 September 2021

Accepted Manuscript published online 17 September 2021 (c) 2021 The authors Published by Bioscientifica Ltd
This work is licensed under a Creative Commons Attribution-NonCommercial 4.0 International License. ded from Bioscientifica.com at 04/26/2023 02:04:53PM 